\title{
IDENTIFICATION OF TWO SUBSTRATES OF FTS_1067 PROTEIN - AN ESSENTIAL VIRULENCE FACTOR OF FRANCISELLA TULARENSIS
}

\author{
Petra Spidlova*, IVA SenitKova, MareK Link and Jiri StUlik \\ Department of Molecular Pathology and Biology, Faculty of Military Health Sciences, \\ University of Defence, Hradec Králové, Czech Republic
}

(Received: 21 March 2016; accepted: 30 August 2016)

\begin{abstract}
Francisella tularensis is a highly virulent intracellular pathogen with the capacity to infect a variety of hosts including humans. One of the most important proteins involved in F. tularensis virulence and pathogenesis is the protein DsbA. This protein is annotated as a lipoprotein with disulfide oxidoreductase/isomerase activity. Therefore, its interactions with different substrates, including probable virulence factors, to assist in their proper folding are anticipated. We aimed to use the immunopurification approach to find DsbA (gene locus FTS_1067) interacting partners in F. tularensis subsp. holarctica strain FSC200 and compare the identified substrates with proteins which were found in our previous comparative proteome analysis. As a result of our work two FTS_1067 substrates, D-alanyl-D-alanine carboxypeptidase family protein and HlyD family secretion protein, were identified. Bacterial two-hybrid systems were further used to test their relevance in confirming FTS_1067 protein interactions.
\end{abstract}

Keywords: bacterial two-hybrid assay, Francisella tularensis, FTS_1067 protein, immunopurification

\section{Introduction}

Francisella tularensis is a Gram negative bacterium that causes the disease tularemia. One of the important $F$. tularensis proteins critical for its virulence is the conserved lipoprotein DsbA (gene locus FTT_1103 in F. tularensis subsp. tularensis strain SchuS4, FTS_1067 in F. tularensis subsp. holarctica strain FSC200, FTL_1096 in F. tularensis subsp. holarctica strain LVS, also referred to as FipB) with proved oxidoreductase and isomerase activities [1-3]. It was shown that the deletion of the gene encoding DsbA led to the high attenuation in vivo associated with the ability to induce host-protective immunity [4, 5]. Recently, it was presumed that the DsbA is not a virulence factor by itself but that its substrates, whose correct

*Corresponding author; E-mail: petra.spidlova@unob.cz 
folding and topology are dependent on the DsbA oxidoreductase and/or isomerase activities, are real virulence factors [2]. Unlike other bacterial periplasmic localized DsbA, $F$. tularensis DsbA protein is outer membrane bounded and lipidated $[6,7]$. Furthermore, F. tularensis DsbA is unusual when compared to other DsbA orthologs; in that it contains N-terminal Forskolin-binding protein-N (FKBP-N) dimerization domain and C-terminal DsbA domain [8].

To find new FTS_1067 interacting partners/substrates in virulent $F$. tularensis subsp. holarctica strain FSC200, we decided to use immunoprecipitation method. The FTS_1067 protein was FLAG-tag labeled and together with its binding partners was purified on the basis of its interaction to covalently bound mouse IgG monoclonal antibody. Protein-protein interactions identified by mass spectrometry analysis were further studied by means of bacterial two-hybrid $(\mathrm{B} 2 \mathrm{H})$ systems. B2H systems were developed as a faster alternative to yeast two hybrid assays. The most of them utilize Escherichia coli transcriptional machinery to detect protein-protein interactions [9]. In these systems, proteins fused to DNA-binding protein [zinc-finger DNA binding domain (Zif) from the murine Zif268 protein] interact with proteins fused to $\omega$ subunit of $E$. coli RNA polymerase (RNAP), which facilitates transcriptional activation of a Zif-dependent $l a c Z$ reporter gene. An alternative, the bacterial adenylate cyclase twohybrid (BACTH) system is based on the reconstitution of adenylate cyclase activity in E. coli cya $^{-}$strain [10-12]. The predicted interacting partners (bait and prays) are fused to the T25 and T18 fragments of adenylate cyclase catalytic domain. If there is an interaction between these two tested proteins, both adenylate cyclase fragments reconstitute the enzyme which leads to cyclic adenosine monophosphate (cAMP) synthesis. The cAMP binds to the catabolite activator protein and this complex turns on the expression of several genes including genes of the mal operon. The bacteria then utilize maltose as a unique source of carbon and can be distinguished on an indicator or selective media.

The goal of present study was to confirm the proposed FTS_1067 proteinprotein interactions reported previously [5] using either immunopurification of FLAG-tagged FTS_1067 protein from trans-complemented $F$. tularensis FSC200/ $\Delta$ FTS_1067 strain or the B2H systems and also to confirm whether these systems are suitable for this purpose.

\section{Materials and Methods}

Bacterial strains, plasmids, and growth conditions

The bacterial strains and plasmids used in this study are listed in Table I. F. tularensis FSC200 and the derivative strains were routinely cultured at $37{ }^{\circ} \mathrm{C}$ 
Table I. Bacterial strains and plasmids used in this study

\begin{tabular}{|c|c|c|}
\hline Strain or plasmid & Relevant characteristics & Source and/or reference \\
\hline \multicolumn{3}{|l|}{ F. tularensis strains } \\
\hline $\begin{array}{l}\text { F. tularensis subsp. } \\
\text { holarctica } \text { strain } \\
\text { FSC } 200\end{array}$ & $\begin{array}{l}\text { Wild-type } F . \text { tularensis subsp. } \\
\text { holarctica, clinical isolate }\end{array}$ & $\begin{array}{l}\text { Francisella strain collection } \\
\text { (FSC) of the Swedish } \\
\text { Defense Research Agency, } \\
\text { Umeå, Sweden }\end{array}$ \\
\hline FSC200/DFTS_1067 & FSC200/Dfts_1067 & {$[5]$} \\
\hline cFSC200/FLAG & $\begin{array}{l}\text { FSC200/ } 2 \text { FTS_1067+pKK289- } \\
\text { FTS_1067FLAG }\end{array}$ & This study \\
\hline \multicolumn{3}{|l|}{ E. coli strains } \\
\hline XL1-Blue & 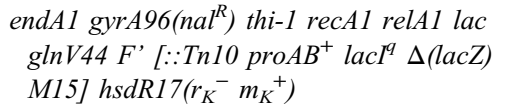 & Stratagene \\
\hline DHM1 & $\begin{array}{c}\mathrm{F}=\text { cya-854 recAl endA1 gyrA96 (Nalr) } \\
\text { thi-1 hsdR17 spoTlrfbD1 glnV44(AS) }\end{array}$ & Euromedex \\
\hline $\mathrm{KDZif1} \Delta \mathrm{Z}$ & $\begin{array}{l}\operatorname{araD}(\text { gpt-lac }) 5, \text { rpsL }\left(\text { str }^{R}\right), \Delta \text { spoS3::cat } \\
\quad\left(\mathrm{Cam}^{R}\right)\left[F^{\prime} \text { lacl }^{q}(\mathrm{Z32} 1[-61] \text { lacZYA*) }\right. \\
\left.\mathrm{Kan}^{R}\right]\end{array}$ & {$[13]$} \\
\hline \multicolumn{3}{|l|}{ Plasmids } \\
\hline pCR4-TOPO & TOPO cloning vector $\mathrm{Amp}^{\mathrm{R}}, \mathrm{Km}^{\mathrm{R}}$ & Invitrogen \\
\hline pKK $289 g f p$ & Ft ori, p15a ori, $\mathrm{Km}^{\mathrm{R}}$, groES promoter & [14] \\
\hline $\begin{array}{l}\text { pKK289- } \\
\text { FTS_1067FLAG }\end{array}$ & $\begin{array}{l}\text { pKK289 with } f t s \_1067 \text { gene fused with } \\
\text { FLAG tag }\end{array}$ & This study \\
\hline pACTR-Ap-Zif & $\mathrm{B} 2 \mathrm{H}$ system plasmid, $\mathrm{Tet}^{\mathrm{R}}$ & {$[13]$} \\
\hline pBRGP- $\omega$ & $\mathrm{B} 2 \mathrm{H}$ system plasmid, $\mathrm{Ap}^{\mathrm{R}}$ & [13] \\
\hline pACTR-Ap-MglA-Zif & pACTR-Ap-Zif with full-length MglA & {$[15]$} \\
\hline pBRGP-SspA- $\omega$ & pBRGP- $\omega$ with full-length SspA & [15] \\
\hline $\begin{array}{l}\text { pACTR-Ap-Zif/ } \\
\text { FTS_0036 }\end{array}$ & pACTR-Ap-Zif with FTS_0036 & This study \\
\hline $\begin{array}{l}\text { pACTR-Ap-Zif/ } \\
\text { FTS_1034 }\end{array}$ & $\begin{array}{l}\text { pACTR-Ap-Zif with FTS_1034 (without } \\
\text { signal sequence) }\end{array}$ & This study \\
\hline 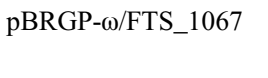 & $\begin{array}{l}\text { pBRGP- } \omega \text { with FTS_1067 (without signal } \\
\text { sequence) }\end{array}$ & This study \\
\hline pKT25 & $\begin{array}{l}\text { BACTH system plasmid carrying T25 } \\
\text { fragment downstream MCS }\end{array}$ & Euromedex \\
\hline pUT18C & $\begin{array}{l}\text { BACTH system plasmid carrying T18 } \\
\text { fragment downstream MCS }\end{array}$ & Euromedex \\
\hline pKT25/FTS_0036 & pKT25 with intact FTS_0036 & This study \\
\hline pUT18C/FTS_0036 & pUT18C with intact FTS_0036 & This study \\
\hline pKT25/FTS_1034 & pKT25 with intact FTS_1034 & This study \\
\hline pUT18C/FTS_1034 & pUT18C with intact FTS_1034 & This study \\
\hline pKT25/FTS_1067 & pKT25 with intact FTS_1067 & This study \\
\hline pUT18C/FTS_1067 & pUT18C with intact FTS_1067 & This study \\
\hline
\end{tabular}

Note: $\mathrm{MCS}=$ multiple cloning site. 
on McLeod agar enriched for bovine haemoglobin (BD Diagnostics, NJ, USA) and IsoVitaleX (BD Diagnostics, NJ, USA). E. coli strains were grown in Luria-Bertani (LB) media or on LB agar plates. When required, kanamycin, $20 \mu \mathrm{g} \mathrm{mL} \mathrm{m}^{-1}$ (F. tularensis) or $50 \mu \mathrm{g} \mathrm{mL}{ }^{-1}$ (E. coli); carbenicillin, $100 \mu \mathrm{g} \mathrm{mL}{ }^{-1}$; tetracycline, $10 \mu \mathrm{g} \mathrm{mL}^{-1}$; ampicillin, $100 \mu \mathrm{g} \mathrm{mL}^{-1}$ or $0.5 \mathrm{mM}$ isopropyl- $\beta$-D-thiogalactopyranoside (IPTG) were used.

\section{Complementation in trans}

The gene coding for FTS_1067 was PCR-amplified using primers FTS_1067-Fw and FTS_1067-Rev (Supplementary Table I) and F. tularensis subsp. holarctica strain FSC200 chromosomal DNA as the template. The reverse primer was designed to introduce DNA sequence coding for FLAG tag (DYKDDDDK) downstream the gene. The PCR fragment was cloned into pCR4-TOPO vector (Invitrogen, Carlsbad, USA) and sequenced (Generi-Biotech, Hradec Kralove, Czech Republic). Using restriction sites for NdeI and SacI enzymes, the fragment was ligated to pKK289KmGFP shuttle vector instead of $g f p$ gene. The final construct was introduced to $F$. tularensis deletion mutant strain FSC200/DFTS_1067 [5] by electroporation [16].

\section{Purification of FTS_1067 interacting partners}

The complemented strain cFSC200/FLAG was grown on McLeod agar plates supplemented with kanamycin for 24-48 h. Then the bacteria were harvested and washed twice with phosphate buffered saline and finally resuspended in lysis buffer [50 mM Tris/HCl, pH 7.4; $150 \mathrm{mM} \mathrm{NaCl} ; 1 \mathrm{mM}$ EDTA; 1\% Triton X-100; protease inhibitor cocktail Complete EDTA-free (Roche, Basel, Switzerland); and Benzonase Nuclease (Sigma-Aldrich, St. Louis, USA)]. The bacterial lysate was prepared using French Press Pressure Cell by three passages at $16,000 \mathrm{psi}$ and the intact bacteria and cell debris were removed by centrifugation $\left(6,500 \mathrm{rpm}, 30 \mathrm{~min}, 4^{\circ} \mathrm{C}\right)$. Anti-FLAG M2 Affinity Gel (SigmaAldrich, St. Louis, USA) was used for immunoprecipitation of the FTS_1067 together with its interacting partners from the cell lysate. The $3 \times$ FLAG peptide (Sigma-Aldrich, St. Louis, USA) which competes with FLAG-tagged protein was used for elution. As a negative control the same procedure was applied using the deletion mutant strain FSC200/DFTS_1067. The presence of FTS_1067 protein in the cell lysate of complemented strain was confirmed by immunodetection using either monoclonal antibody raised against FLAG tag epitope (Anti-FLAG M2 monoclonal antibody, Sigma-Aldrich, St. Louis, USA) or polyclonal antibody against FTS_1067 protein (Apronex, Vestec, Czech Republic). 
Identification of proteins

The liquid chromatography-matrix assisted laser desorption/ionization (LCMALDI) workflow was applied for identification of FTS_1067 interacting partners. First, the excess of $3 \times$ FLAG peptide was removed by methanol/chloroform extraction [17] and the sample was resuspended in 0.1\% RapiGest ST Surfactant (Waters, Milford, USA). Following reduction and alkylation, the proteins were digested by trypsin (Promega, Madison, USA). Peptides were separated on an Atlantis $\mathrm{dC} 183 \mu \mathrm{m}, 0.075 \times 150-\mathrm{mm}$ column and fractions were collected on MALDI target plate using the Probot (Dionex, Sunnyvale, USA). The mass spectrometric analysis was performed on a 4800 MALDI TOF/TOF Analyzer (AB Sciex, Framingham, USA). The mass spectra of peptides were acquired from 800 to $4,000 \mathrm{~m} / \mathrm{z}$ window in the reflector positive ion mode first, followed by tandem mass spectra acquisition on automatically selected precursor ions. Peptide and protein identifications were performed using ProteinPilot 2.0 software (AB Sciex, Framingham, USA). The data were searched against $F$. tularensis subsp. holarctica FSC200 database (UniProt, containing 1,420 entries) with appended common contaminant sequences. The proteins identified by at least one unique high confident peptide, as reported by ProteinPilot software, were considered for further evaluation. The respective protein was claimed as a potential substrate of FTS_1067 if it was identified in the immunoprecipitate from the complemented strain carrying the FTS_1067 gene and was undetected in the control sample. The potential substrates of FTS_1067 identified in both biological replicates are reported.

\section{B2H and $\beta$-galactosidase assays}

Sequence coding for FTS_1067 protein without signal sequence was in frame cloned to pBRGP- $\omega$ plasmid [13] and sequence coding for FTS_0036 and FTS_1034 (without signal sequence) were cloned to pACTR-Ap-Zif plasmid [13]. All plasmid constructs were sequenced. Plasmids and primers used in this assay are listed in Table I and Supplementary Table I, respectively. Plasmids carrying the - Zif and $-\omega$ fusions were cotransformed into E. coli KDZif1 $\Delta Z$ [13]. Several clones were inoculated to LB medium containing appropriate antibiotics and grown overnight. Overnight cultures were diluted in fresh LB medium supplemented with antibiotics and $0.5 \mathrm{mM}$ IPTG and grown to $\mathrm{OD}_{600} 0.5-0.6$ and assayed for $\beta$-galactosidase activity [9]. As a negative control, E. coli KDZif1 $\Delta Z$ were cotransformed by empty pACTR-Ap-Zif and pBRGP- $\omega$ plasmids; and as a positive control by plasmids pACTR-Ap-MglA-Zif and pBGRP-SspA- $\omega$ [15]. The empty plasmid pBRGP- $\omega$ together with FTS_1067-Zif was used as another negative control. 


\section{BACTH assay}

We performed the BACTH assay according to Battesti and Bouveret's [18] instructions. Briefly, protein FTS_1067 and proteins of interest were fused with both, the T18 adenylate cyclase fragment (in frame fusions at the C-terminal end of T18 and in frame fusions at the N-terminal end of T18) and the T25 adenylate cyclase fragment (in frame fusions at the $\mathrm{C}$-terminal end of $\mathrm{T} 25$ and in frame fusions at the N-terminal end of T25). All plasmid constructs were sequenced. Plasmids and primers used in this assay are listed in Table I and Supplementary Table I, respectively. For each assay, E. coli DHM1 chemocompetent cells were transformed by $0.5 \mu \mathrm{L}$ of the two plasmids carrying the T25 and T18 fusions and spread on LB plates containing $100 \mu \mathrm{g} \mathrm{mL}-1$ ampicillin and $50 \mu \mathrm{g} \mathrm{mL}^{-1}$ kanamycin and incubated for 2 days at $30{ }^{\circ} \mathrm{C}$. Several clones were inoculated to $3 \mathrm{~mL}$ of LB containing $100 \mu \mathrm{g} \mathrm{mL}^{-1}$ ampicillin, $50 \mu \mathrm{g} \mathrm{mL}^{-1}$ kanamycin, and $0.5 \mathrm{mM}$ IPTG and incubated overnight at $30^{\circ} \mathrm{C}$. The next day, $2 \mu \mathrm{L}$ of each culture were dropped on MacConkey/maltose plates containing appropriate antibiotics and IPTG; and LB plates supplemented with appropriate antibiotics, IPTG and X-Gal (5-bromo-4-chloro-3-indolyl- $\beta$-D-galactopyranoside, $40 \mu \mathrm{g} \mathrm{mL}{ }^{-1}$ ). The plates were then incubated several days at $30^{\circ} \mathrm{C}$ until a red/blue coloration appears. Two empty pUT18 and pKNT25 plasmids were used as a negative control, plasmids pKT25-zip and pUT18C-zip carrying leucine zipper of GCN4 [10] fused in frame to the T25 and T18 were used as a positive control. As another negative control, empty pUT18C and pKT25 plasmids together with pKT25 and pUT18C plasmids carrying FTS_1067 were used. As another positive control pUT18C and pKT25 plasmids carrying $F$. tularensis iglA, and iglB genes, respectively, were used. IglA-IglB interaction has been previously demonstrated in F. tularensis [19].

\section{Results}

In order to purify and identify the candidate binding partners/substrates of FTS_1067 protein, we trans-complemented the FTS_1067 deletion mutant strain with the shuttle vector pKK289Km carrying the intact gene coding for FTS_1067 fused with the sequence encoding FLAG tag epitope. The presence of FTS_1067 protein in the cell lysate of complemented strain was confirmed by immunodetection using either Anti-FLAG M2 monoclonal antibody or polyclonal antibody raised against FTS_1067 protein (Figure 1). The theoretical molecular weight of FTS_1067 is $39 \mathrm{kDa}$, but it is known that the protein is post-translationally modified by glycosylation [20,21], which increases its molecular weight. We detected the protein band migrating around $50 \mathrm{kDa}$ by both antibodies, proving 
(A)

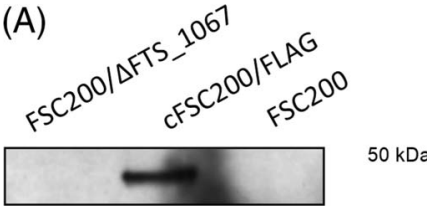

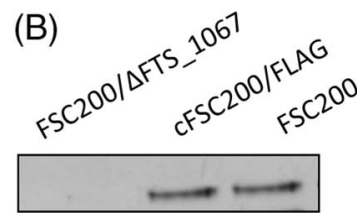

Figure 1. Detection of FTS_1067 protein in trans-complemented strain. The bacterial cell lysates prepared from the deletion mutant strain FSC200/DFTS_1067, the trans-complemented strain cFSC200/FLAG, and the FSC200 were separated on SDS-PAGE, then transferred to PVDF membrane by using semi-dry Western blotting procedure, and proteins were visualized using Anti-FLAG M2 monoclonal antibody (A) and polyclonal antibody against FTS_1067 protein (B)

that the protein FTS_1067 is produced in the complemented strain. The amount of FTS_1067 protein in trans-complemented strain is comparable to that of wild-type strain, which was documented earlier [3].

Previously, it was demonstrated that the deletion of gene coding for the FTT_1103 or FTS_1067 resulted in the attenuation in mouse model of infection and in the defect in proliferation in vitro $[4,5]$. Therefore, the effect of complementation was also studied by in vitro proliferation of the complemented strain in murine bone marrow-derived macrophages. The proliferation was compared to those of the wild-type FSC200 and the deletion mutant FSC200/ $\Delta$ FTS_1067 strains and showed that the complemented strain is able to proliferate in this cell line comparably to the wild-type strain FSC200 [3], which suggests the production of fully functional FTS_1067 protein in the complemented strain.

In our study, we tried to purify and identify FTS_1067 substrates by immunoprecipitation. Following immunoprecipitation and elution the complex with $3 \times$ FLAG peptide, the proteins were digested and analyzed by LC-MALDI. Two biological replicates were prepared and only potential substrates of FTS_1067 identified in both replicates on at least two peptides were accepted and are summarized in Table II. These proteins are HlyD family secretion protein FTS_0036 and D-alanyl-D-alanine carboxypeptidase (penicillin-binding protein) family protein FTS_1034 (DacD). As expected, protein FTS_1067 was identified only in the precipitate from the complemented strain and not detected in the control sample (Supplementary Table II). The other identified proteins that did not fulfil the above-mentioned criteria were omitted.

Recently, it was shown that both FTS_1067 and FTT_1103 proteins need to be reduced to act as an isomerase or oxidoreductase $[1,3]$. Due to this fact, we decided to further validate the observed protein-protein interactions by using an independent approach, the $\mathrm{B} 2 \mathrm{H}$ systems where the interactions take place in reducing cytoplasm. 
Table II. Substrates of FTS_1067 identified from immunoprecipitation experiments

\begin{tabular}{|c|c|c|c|c|c|}
\hline & $\begin{array}{l}\text { UniProt } \\
\text { ID }\end{array}$ & Protein name & $\begin{array}{l}\text { ORF } \\
\text { name }\end{array}$ & $\begin{array}{c}\text { Peptide ID } \\
\text { confidence } \\
(\%)\end{array}$ & Peptide sequence \\
\hline \multirow[t]{6}{*}{$\begin{array}{l}\text { Biological } \\
\text { replicate I }\end{array}$} & K0E1G6 & $\begin{array}{l}\text { HlyD family } \\
\text { membrane } \\
\text { fusion protein }\end{array}$ & FTS_0036 & 99 & ATTNGYISNFILEEGDFIK \\
\hline & & & & 99 & DAYLYADFTR \\
\hline & & & & 99 & GITRPEYNNFSALYNIER \\
\hline & & & & 99 & SLISSESQFIR \\
\hline & K0E6Y1 & $\begin{array}{l}\text { D-alanyl- } \\
\text { D-alanine } \\
\text { carboxypeptidase }\end{array}$ & FTS_1034 & 99 & TGHTDAAGYCLVSSVK \\
\hline & & & & 98 & GDNFVLQNNR \\
\hline \multirow[t]{5}{*}{$\begin{array}{l}\text { Biological } \\
\text { replicate II }\end{array}$} & K0E1G6 & $\begin{array}{l}\text { HlyD family } \\
\text { membrane } \\
\text { fusion protein }\end{array}$ & FTS_0036 & 99 & GITRPEYNNFSALYNIER \\
\hline & & & & 98 & SLISSESQFIR \\
\hline & K0E6Y1 & $\begin{array}{l}\text { D-alanyl- } \\
\text { D-alanine } \\
\text { carboxypeptidase }\end{array}$ & FTS_1034 & 99 & GDNFVLQNNR \\
\hline & & & & 99 & SYIYNFPEAYK \\
\hline & & & & 99 & TGHTDAAGYCLVSSVK \\
\hline
\end{tabular}

Note: $\mathrm{ORF}=$ open reading frame; ID = identification. The peptide sequences and peptide identification confidence identified for each protein are shown.

First, we employed the $E$. coli $\mathrm{B} 2 \mathrm{H}$ system, where the amount of produced $\beta$-galactosidase is proportional to the strength of protein-protein interaction [9]. The protein FTS_1067 was fused to the N-terminus of $\omega$ subunit of RNAP and proteins of interest were fused to the N-terminus of Zif. In silico analyses performed with tested proteins showed that FTS_1067 and FTS_1034 contain N-terminal signal sequence (SignalP 4.0) [22]. To prevent secretion of FTS_1067 and FTS_1034 fusion proteins outside the cytoplasm, the signal sequences of these proteins were omitted. Unfortunately, the measurements of the $\beta$-galactosidase activity (Figure 2) did not prove the interaction of FTS_1067 with either of the two tested proteins. Similarly, all other proteins identified in the comparative proteome study [5] yielded negative results when assayed for the interactions as well (Pavkova and Schmidt, personal communications).

As a second option of the B2H system, we chose the BACTH assay [10]. The proteins of interest were fused to both T18 and T25 adenylate cyclase domains, and similarly, the FTS_1067 was fused to either T18 or T25 adenylate cyclase domains. Both genetic fusions at either the $\mathrm{C}$ - or $\mathrm{N}$-termini of respective adenylate cyclase domains were constructed in order to avoid a possible shift of 


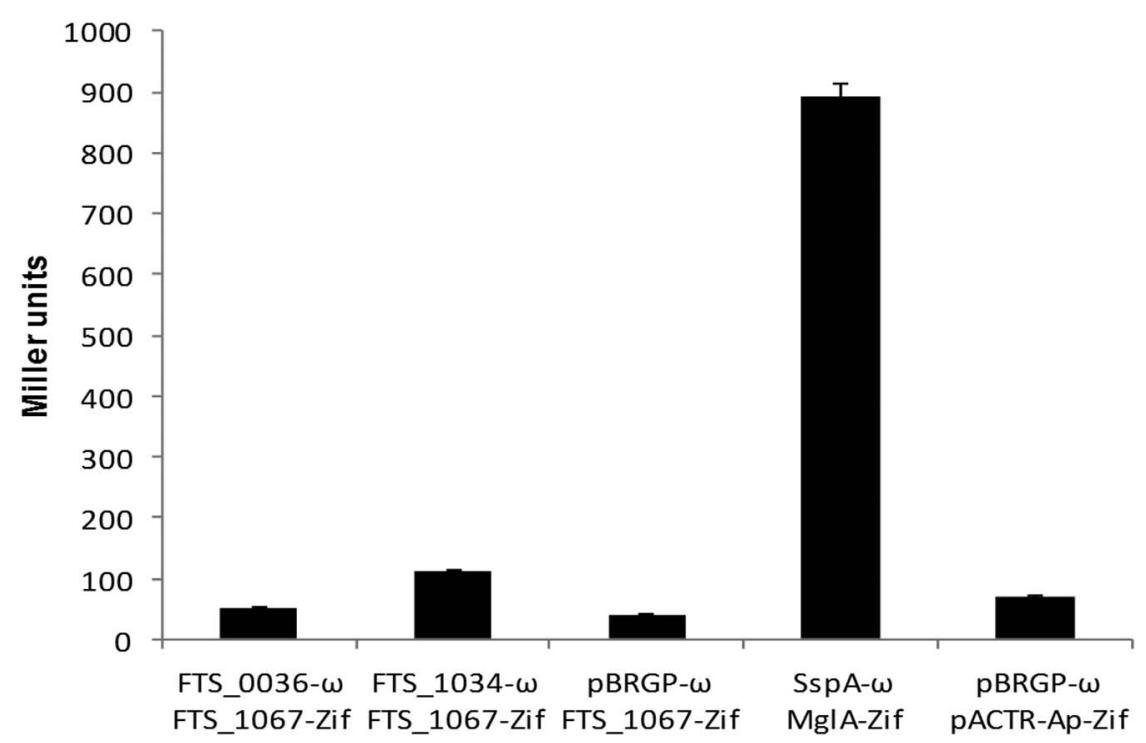

Figure 2. Bacterial two-hybrid analysis. Reporter strain $E$. coli KDZif1 $\Delta Z$ carrying plasmids with -Zif and $-\omega$ fusions was subjected to measurements of $\beta$-galactosidase activity. As a positive control, MglA-Zif and SspA- $\omega$ fusions were used. As a negative control, two empty pACTR-Ap-Zif and pBRGP- $\omega$ plasmids were used. The mean value for $\beta$-galactosidase activity (in Miller units) \pm standard deviation from two independent experiments including two independent transformants is shown

monitored fusion proteins into periplasm, where the ATP is missing. All combinations of plasmids carrying the T18 and the T25 fusions were tested and gave us the negative results. The results shown in Figure 3 are from experiment where all tested proteins were fused to the C-terminus of either T18 or T25 adenylate cyclase domains. Only the test of the interaction between IglA and IglB proteins, which has been previously described [19], provided a positive signal (Figure $3-\mathrm{I}$ and $\mathrm{J}$ ).

\section{Discussion}

Protein DsbA belongs to the most studied $F$. tularensis proteins because of its key role in Francisella virulence [1-5, 21, 23]. In fact, the role of DsbA protein in virulence is indirect and depends on its correct oxidoreductase $[1,5,23]$ and recently confirmed isomerase activities [1-3]. Hence, it is highly desirable to identify the FTS_1067 substrates that might be responsible for the FTS_1067 contribution to $F$. tularensis subsp. holarctica strain FCS200 pathogenesis. 


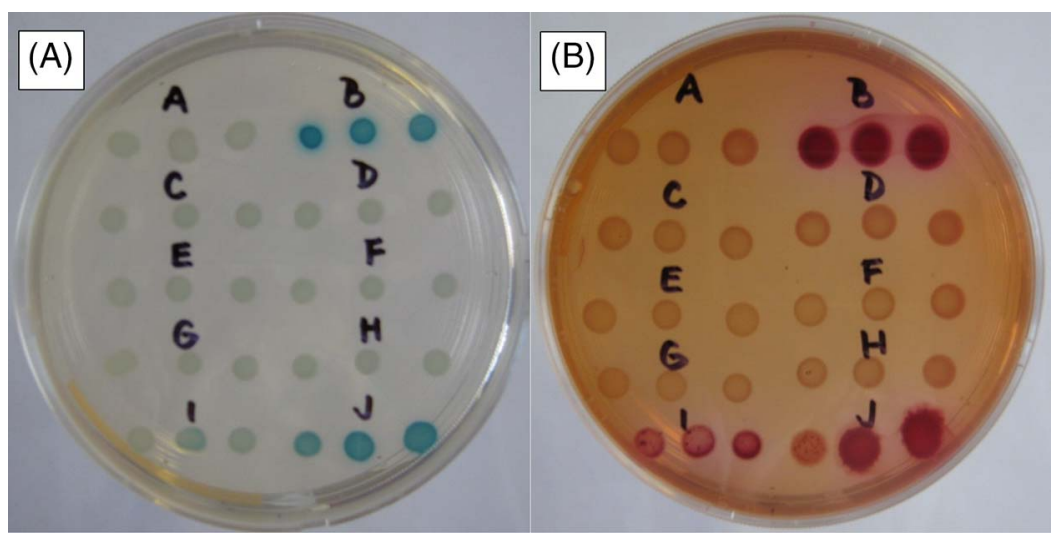

Figure 3. BACTH assay. Test of protein-protein interactions between FTS_1067 and proteins of interest. $2 \mu \mathrm{L}$ of $E$. coli DHM1 bacterial cultures carrying pKT25 and pUT18C derivatives were dropped onto indicator plates. Three colonies were chosen for each tested pair. (A) LB plate supplemented with kanamycin, ampicillin, IPTG, and X-Gal. (B) MacConkey plate supplemented with kanamycin, ampicillin, maltose, and ITPG. A-BACTH negative control, B-BACTH positive control, C-FTS_0036pUT18C+FTS_1067pKT25, D-FTS_0036pKT25 + FTS_1067pUT18C,

E-FTS_1034pUT18C+FTS_1067pKT25, F-FTS_1034pKT25 + FTS_1067pUT18C, G-pUT18C + FTS_1067pKT25, H-pKT25 + FTS_1067pUT18C, I-IglApUT18C + IglBpKT25, and J-IglApKT25 + IglBpUT18C

The first protein revealed by our immunoproteomic approach was D-alanylD-alanine carboxypeptidase family protein FTS_1034. The same protein was identified also in our proteome study reported previously [5], which suggest that this is indeed a substrate of FTS_1067. The D-alanyl-D-alanine carboxypeptidase family protein FTS_1034 belongs to the protein family of penicillin-binding proteins. The members of this family catalyze final transpeptidase reaction during the bacterial wall biosynthesis. The homolog of this protein in Brucella abortus is a known virulence factor [24]. Very recently the FTT_1029 protein, the homolog of FTS_1034 in SchuS4 strain, was described as an uncharacterized virulence factor candidate [25]. The amino acid sequence of the FTS_1034 contains 3 cysteine residues; one of them seems to be involved in an inter-molecular disulfide bond formation [26-28].

The second identified protein, HlyD family secretion protein FTS_0036, belongs to the family of membrane fusion proteins, which are responsible for the export of many compounds across the membrane and is essential for the HlyA secretion in E. coli [29]. Its protein sequence contains four cysteine residues; thus it might be a substrate for FTS_1067 protein although the prediction (DiANNA 1.1 web server) suggests that all residues are in the form of free-cysteines. 
We tried to verify these two proteins as substrates of FTS_1067 using B2H assays and thus found out their applicability in confirming non-cytoplasmic protein interactions. But, both tested $\mathrm{B} 2 \mathrm{H}$ systems gave us negative results. One should argue that the cytoplasm, where interactions in $\mathrm{B} 2 \mathrm{H}$ assays take place is reducing environment and that the FTS_1067 must be in oxidized state to act as an oxidoreductase or isomerase. But as was mentioned above, the results of our group [3] and the results by Qin et al. [1] indicate that both oxidoreductase and isomerase activities of FTS_1067 or FTT_1103 are dependent on their reduced state and thus, the reducing environment in cytoplasm should not be limiting.

Recently, Ren et al. [2] published a study on the identification of FTL_1096 substrates. They identified more than 50 FTL_1096 substrates using trapping experiments. Among the identified proteins also, the proteins FTL_0038 (FTS_0036), FTL_1060(FTS_1034), FTL_1306(FTS_1279), FTL_1521 (FTS_1485), FTL_1532 (FTS_1495), and FTL_1579 (FTS_1538) from our study and from the study by Straskova et al. [5] which gave negative results in B2H assays have been documented.

It seems that the FTS_1067 and its substrates need to be located outside the cytoplasm in order to preserve their interactions and thus they are undetectable for $\mathrm{B} 2 \mathrm{H}$ systems. We cannot also rule out the existence of other auxiliary protein which assists the protein FTS_1067.

To conclude, using the immunoprecipitation approach, we identified D-alanyl-D-alanine carboxypeptidase family protein FTS_1034 and HlyD family secretion protein FTS_0036 as substrates of the FTS_1067 protein in a fully virulent isolate of $F$. tularensis subsp. holarctica strain FSC200. Although our attempts to verify these protein-protein interactions using $\mathrm{B} 2 \mathrm{H}$ systems failed, the results obtained from independent study performed on vaccine strain [2] strongly support their in vivo existence.

\section{Acknowledgements}

The authors would like to thank Åke Forsberg for the gift of pKK289KmGFP plasmid and Jeanette E. Bröms and Simon L. Dove for providing the bacterial two-hybrid system. This work was supported by Ministry of Defence, Czech Republic Long-term Organization Development Plan 1011 and The Specific Research of Faculty of Military Health Sciences, University of Defence, Czech Republic (Grant No. FVZ0000604).

\section{Conflict of Interest}

The authors have no conflict of interest to declare. 


\section{References}

1. Qin, A., Zhang, Y., Clark, M. E., Rabideau, M. M., Millan Barea, L. R., Mann, B. J.: FipB, an essential virulence factor of Francisella tularensis subsp. tularensis, has dual roles in disulfide bond formation. J Bacteriol 196, 3571-3581 (2014).

2. Ren, G., Champion, M. M., Huntley, J. F.: Identification of disulfide bond isomerase substrates reveals bacterial virulence factors. Mol Microbiol 94, 926-944 (2014).

3. Senitkova, I., Spidlova, P., Stulik, J.: Cooperation of both, the FKBP_N-like and the DSBA-like, domains is necessary for the correct function of FTS_1067 protein involved in Francisella tularensis virulence and pathogenesis. Pathog Dis 73, ftv030 (2015).

4. Qin, A., Scott, D. W., Thompson, J. A., Mann, B. J.: Identification of an essential Francisella tularensis subsp. tularensis virulence factor. Infect Immun 77, 152-161 (2009).

5. Straskova, A., Pavkova, I., Link, M., Forslund, A.-L., Kuoppa, K., Noppa, L., Kroca, M., Fucikova, A., Klimentova, J., Krocova, Z., Forsberg, A., Stulik, J.: Proteome analysis of an attenuated Francisella tularensis dsbA mutant: Identification of potential DsbA substrate proteins. J Proteome Res 8, 5336-5346 (2009).

6. Huntley, J. F., Conley, P. G., Hagman, K. E., Norgard, M. V.: Characterization of Francisella tularensis outer membrane proteins. J Bacteriol 189, 561-574 (2007).

7. Thakran, S., Li, H., Lavine, C. L., Miller, M. A., Bina, J. E., Bina, X. R., Re, F.: Identification of Francisella tularensis lipoproteins that stimulate the toll-like receptor (TLR) 2/TLR1 heterodimer. J Biol Chem 283, 3751-3760 (2008).

8. Qin, A., Scott, D. W., Rabideau, M. M., Moore, E. A., Mann, B. J.: Requirement of the CXXC motif of novel Francisella infectivity potentiator protein B FipB, and FipA in virulence of $F$. tularensis subsp. tularensis. PLoS One 6, e24611 (2011).

9. Dove, S. L., Hochschild, A.: A bacterial two-hybrid system based on transcription activation. Methods Mol Biol 261, 231-246 (2004).

10. Karimova, G., Pidoux, J., Ullmann, A., Ladant, D.: A bacterial two-hybrid system based on a reconstituted signal transduction pathway. Proc Natl Acad Sci U S A 95, 5752-5756 (1998).

11. Karimova, G., Ullmann, A., Ladant, D.: A bacterial two-hybrid system that exploits a cAMP signaling cascade in Escherichia coli. Methods Enzymol 328, 59-73 (2000).

12. Ladant, D., Ullmann, A.: Bordatella pertussis adenylate cyclase: A toxin with multiple talents. Trends Microbiol 7, 172-176 (1999).

13. Vallet-Gely, I., Donovan, K. E., Fang, R., Joung, J. K., Dove, S. L.: Repression of phasevariable cup gene expression by H-NS-like proteins in Pseudomonas aeruginosa. Proc Natl Acad Sci U S A 102, 11082-11087 (2005).

14. Bönquist, L., Lindgren, H., Golovliov, I., Guina, T., Sjöstedt, A.: MglA and Igl proteins contribute to the modulation of Francisella tularensis live vaccine strain-containing phagosomes in murine macrophages. Infect Immun 76, 3502-3510 (2008).

15. Charity, J. C., Costante-Hamm, M. M., Balon, E. L., Boyd, D. H., Rubin, E. J., Dove, S. L.: Twin RNA polymerase-associated proteins control virulence gene expression in Francisella tularensis. PLoS Pathog 3, e84 (2007).

16. Rodriguez, S. A., Yu, J.-J., Davis, G., Arulanandam, B. P., Klose, K. E.: Targeted inactivation of Francisella tularensis genes by group II introns. Appl Environ Microbiol 74, 2619-2626 (2008). 
17. Hilder, T. L., Malone, M. H., Bencharit, S., Colicelli, J., Haystead, T. A., Johnson, G. L., $\mathrm{Wu}$, C. C.: Proteomic identification of the cerebral cavernous malformation signaling complex. J Proteome Res 6, 4343-4355 (2007).

18. Battesti, A., Bouveret, E.: The bacterial two-hybrid system based on adenylate cyclase reconstitution in Escherichia coli. Nat Methods 58, 325-334 (2012).

19. Bröms, J. E., Lavander, M., Sjöstedt, A.: A conserved alpha-helix essential for a type VI secretion-like system of Francisella tularensis. J Bacteriol 191, 2431-2446 (2009).

20. Balonova, L., Hernychova, L., Mann, B. F., Link, M., Bilkova, Z., Novotny, M. V., Stulik, J.: Multimethodological approach to identification of glycoproteins from the proteome of Francisella tularensis, an intracellular microorganism. J Proteome Res 9, 1995-2005 (2010).

21. Thomas, R. M., Twine, S. M., Fulton, K. M., Tessier, L., Kilmury, S. L. N., Ding, W., Harmer, N., Michell, S. L., Oyston, P. C. F., Titball, R. W., Prior, J. L.: Glycosylation of DsbA in Francisella tularensis subsp. tularensis. J Bacteriol 193, 5498-5509 (2011).

22. Petersen, T. N., Brunak, S., von Heijne, G., Nielsen, H.: SignalP 4.0, discriminating signal peptides from transmembrane regions. Nat Methods 8, 785-786 (2011).

23. Schmidt, M., Klimentova, J., Rehulka, P., Straskova, A., Spidlova, P., Szotakova, B., Stulik, J., Pavkova, I.: Francisella tularensis subsp. holarctica DsbA homologue: A thioredoxin-like protein with chaperone function. Microbiology 159, 2364-2374 (2013).

24. Kikuchi, H., Kim, S., Watanabe, K., Watarai, M.: Brucella abortus D-alanyl-D-alanine carboxypeptidase contributes to its intracellular replication and resistance against nitric oxide. FEMS Microbiol Lett 259, 120-125 (2006).

25. Wallqvist, A., Memišević, V., Zavaljevski, N., Pieper, R., Rajagopala, S. V., Kwon, K., Yu, C., Hoover, T. A., Reifman, J.: Using host-pathogen protein interactions to identify and characterize Francisella tularensis virulence factors. BMC Genomics 16, 1106 (2015).

26. Ferrè, F., Clote, P.: DiANNA: A web server for disulfide connectivity prediction. Nucleic Acids Res 33, W230-W232 (2005).

27. Ferrè, F., Clote, P.: Disulfide connectivity prediction using secondary structure information and diresidue frequencies. Bioinformatics 21, 2336-2346 (2005).

28. Ferrè, F., Clote, P.: DiANNA 1.1: An extension of the DiANNA web server for ternary cysteine classification. Nucleic Acids Res 34, W182-W185 (2006).

29. Pimenta, A. L., Racher, K., Jamieson, L., Blight, M. A., Holland, I. B.: Mutations in HlyD, part of the type 1 translocator for hemolysin secretion, affect the folding of the secreted toxin. J Bacteriol 187, 7471-7480 (2005). 